\title{
A Centering Technique for Cast-Iron Moulds in Horizontal Centrifugal Casting
}

\author{
Leopold Hrabovský1*, Ivan Mašlonka², Tomáš Kubín ${ }^{3}$, Martin Mantič ${ }^{4}$
}

1 VSB Technical University of Ostrava, Faculty of Mechanical Engineering, Institute of Transport, 17. listopadu 2172/15, 70800 Ostrava - Poruba, Czech Republic

2 KonCAD CZ s.r.o., Hlubinská 917/20, 70200 Moravská Ostrava, Czech Republic

3 VSB Technical University of Ostrava, Faculty of Mechanical Engineering, Department of Production Machines and Design, 17. listopadu 2172/15, 70800 Ostrava - Poruba, Czech Republic

${ }^{4}$ Technical University of Košice, Faculty of Mechanical Engineering, Institute of design machine and process engineering, Letná 9 Street, 04200 Košice, Slovak Republic

*Corresponding author's email: leopold.hrabovsky@vsb.cz

\begin{abstract}
In this paper, a technique of axial centering of cast-iron moulds, e.g. the so-called "rail system" as suggested by KonCAD CZ s.r.o. for the application of horizontal centrifugal metal casting process, was described, evaluated, and finally not recommended for practical use. The proposed principle of the axial centering technique is based on the fact that two rings with the external shape similar to the shape of the Vignole (flat-bottomed) rail are welded on the cast-iron mould external perimeter, perpendicularly to the cast-iron longitudinal centreline. The cast-iron moulds are supported by two pairs of opposite conic rollers. The cast-iron mould is driven by a contact power transmission, i.e. by the friction method employing a pair of conical rollers and acting over the welded rings to the cast-iron mould. The circumferential force transfer is carried out by the friction between the cast-iron mould rings and the two driving rollers. Both driving and driven rollers have similar shapes, analogous to a tyred wheel profile. The two driving rollers are tightly fit on the common drive shaft, the centreline of which runs in parallel with the cast-iron mould longitudinal centreline. The necessity of creating of a sufficient thrust force of the cast-iron mould against the rollers causes wear conditions at the rounding of external shapes of rings, bearings, as well as roller contact conic surfaces.
\end{abstract}

Keywords: centrifugal casting, centering of cast-iron moulds, driving conical roller, friction drive.

\section{INTRODUCTION}

One of the methods for manufacturing half-products with hollow cross-section is the centrifugal casting technique $[6,16]$, where molten metals are poured into casting moulds or cast-iron moulds. The principle of horizontal centrifugal casting [12] consists in melting of the required alloys in a furnace and consequently pouring them to a casting machine, which rotates along its axis; due to the centrifugal forces, the alloy is accumulated at the casting machine walls until it is cooled off and solidified.
The high quality of centrifugal castings predetermines them for use under heavy duty conditions [9]. Due to the centrifugal forces [10], porosity and impurities (if any) occur only at the casting inner surface (to be removed during consequent finishing). The manufacturing process of centrifugal castings is as follows: in a centrifugal casting the melted metal is poured into a fast rotating metal mould [2, 4]. When poured, the metal is forced by the centrifugal force against the mould walls [3]. The generated pressure assures tight contact between the metal and the mould. 
Gases and intrusions are conveyed towards the centre of rotation, onto the inner section of the casting which is removed by the following machining [1]. The casting gradually solidifies in the direction from the wall towards the axis of rotation. The remaining melted metal is pushed into casting cavities and this improves the casting homogeneity [13].

According to the axis of rotation of the cast-iron mould, centrifugal casting types may be $[7,11,14,16]$ either horizontal (Figure 1) or vertical (Figure 2).

The horizontal casting technique is usually used for the manufacturing of larger-sized castings, while the vertical casting technique is applied for the casting of smaller-sized castings or in the cases, where the cast-piece external diameter is larger than its length. The following centrifugal casting techniques are used [7]: basic centrifugal casting, semi-centrifugal casting, and casting in centrifugal machines [6].

At present, two principles of axial centering of cast-iron moulds are employed, using either radial (Figure 3a) or axial (Figure 3b) rollers.

In the course of horizontal casting, an uneven (fluctuating) increase in the cast-iron mould temperature takes place, which causes changes in the cast-iron mould basic dimensions, particularly an expansion in its length and increased diameter of the cast-iron mould. This negatively influences the method of cast-iron moulds centering by radial rollers (Figure 3a), because the pressure from the roller side surface is applied to the side groove surface at the cast-iron mould. As the same time, this load may be also created by an inaccurate adjustment of the rollers (i.e. they are not truly perpendicular to the cast-iron mould).

During the cast-iron mould centering by the axial rollers (Figure 3b), knocking of the cast-iron mould ring to axial rollers occurs. Due to this, the rollers are strongly damaged.

Institute of Transport, Faculty of Mechanical Engineering, VSB-Technical University of Ostrava was approached by KonCAD CZ s.r.o. with a request for technical assistance in the design of a rail system for axial centering of cast-iron moulds [4].

Theoretical aspects of axial centering of cast-iron moulds by the rail system

In its conceptual design of the centrifugal casting machine - HOLS200 for VÚHŽ a.s. [14] - KonCAD CZ s.r.o. [8] assumed to design and use a new technique of axial centering of cast-iron moulds by the so-called "rail system" (see Figure 4). This technique of axial centering of cast-iron moulds utilised the findings acquired

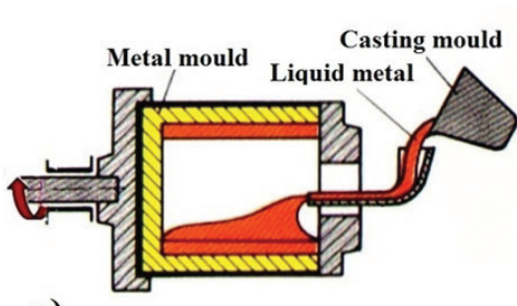

a)
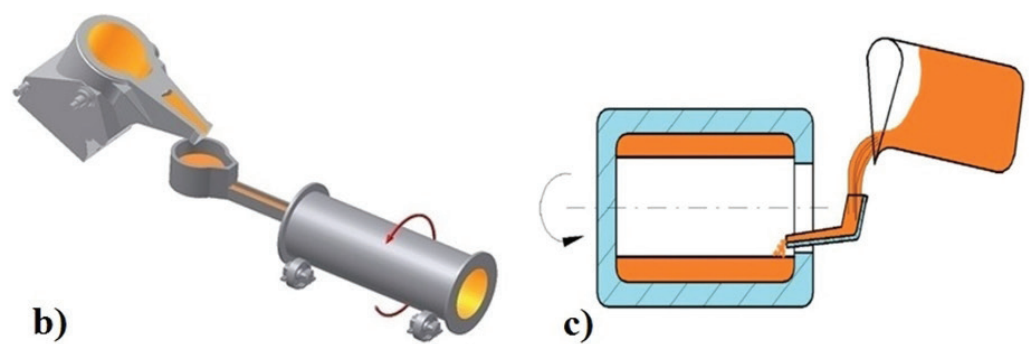

Fig. 1. Horizontal centrifugal casting a) [7], b) [14], c) [11]
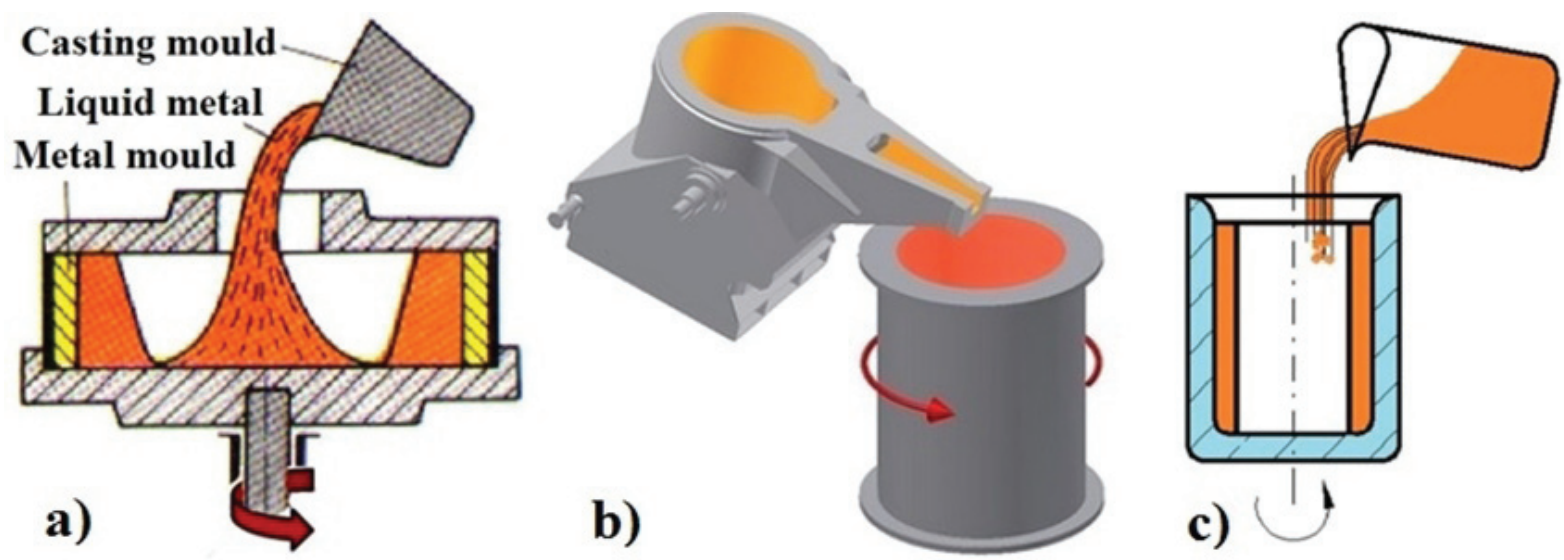

Fig. 2. Vertical centrifugal casting a) [7], b) [14], c) [11] 


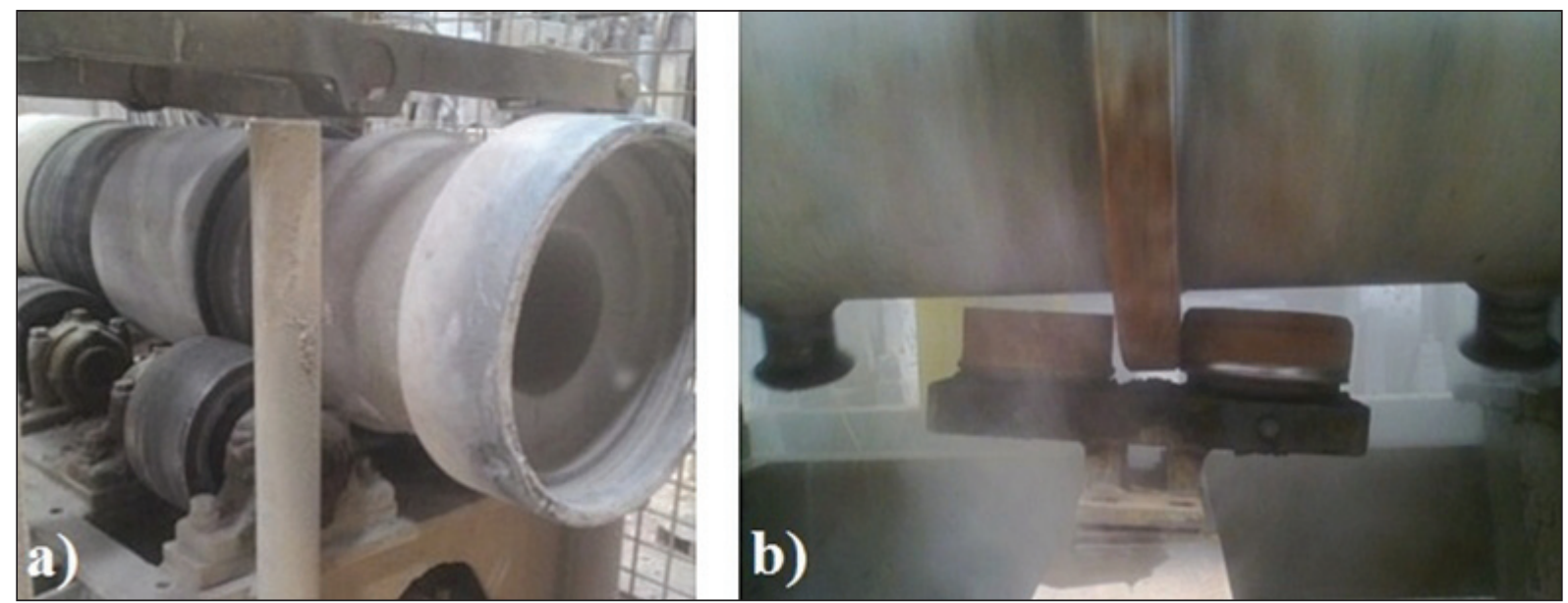

Fig. 3. Axial centering of cast-iron moulds [8] by a) radial, b) axial rollers

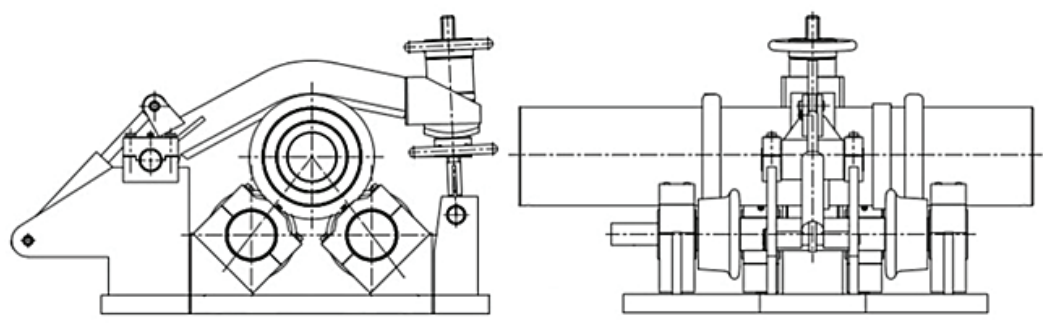

a)

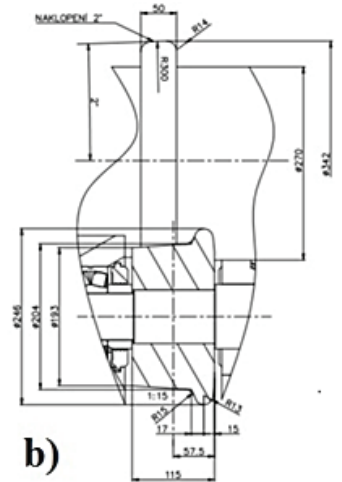

b)

Fig. 4. Rail system of cast-iron mould centering [8] a) 2D draft design, b) conical roller

from the phenomenon of "passing of a rail vehicle through a curved track" [15]. The shape of rolling surface of a pair of railway wheels consist in the so-called "worn surface profile", which means that on the external wheel side it has a smaller diameter and on the internal wheel side (at the wheel flange) a larger diameter. While passing the curved track, and if the pair of railway wheels has a fixed axle and both wheels run with the same revolutions, the inner wheel rolls along a smaller perimeter; thus, its circumferential speed is lower. The outer wheel rolls along a larger perimeter and, due to this, its circumferential speed is higher. By shifting of the pair of wheels from the track centreline towards the outer rail will result in such an effect where the circles of contact of both wheels define a cone with its apex in the centre of the curve and the pair of wheels passes through the curved track without rotational wheel (longitudinal) slips.

For the purposes on this calculation, the centre of gravity $\mathrm{T}$ (Figure 5) of a cast-iron mould weighing $\mathrm{GC}[\mathrm{N}]$ was chosen in the middle of the length Lk [m] of the cast-iron mould. The edges of the cast-iron mould rings contacting the roller cone surfaces are distanced by the value of $\mathrm{L} 1[\mathrm{~m}]$ and L1 + L2 [m] from the left-hand front edge of the cast-iron mould.

The distance of the contact point of the left/ right ring of the cast-iron mould with supporting cone rollers from the centre of gravity $\mathrm{T}$ of the cast-iron mould can be expressed according to the following relation (1).

$$
\mathrm{a}=\frac{\mathrm{L}_{\mathrm{k}}}{2}-\mathrm{L}_{1}, \mathrm{~b}=\frac{\mathrm{L}_{\mathrm{k}}}{2}-\mathrm{L}_{3}[\mathrm{~m}]
$$

From equation of moments (3), the magnitude of the reaction R1 can be expressed, see (4). By modifying the relation (2) and use of the relation (3), the magnitude of the reaction $\mathrm{R} 2$, can be expressed as follows, see (4).

$$
\begin{aligned}
& \sum \mathrm{F}_{\mathrm{y}}=0: 2 \cdot \mathrm{R}_{1}+2 \cdot \mathrm{R}_{2}=\mathrm{G}_{\mathrm{c}}[\mathrm{N}] \\
& \sum \mathrm{M}_{2}=0: 2 \cdot \mathrm{R}_{1} \cdot \mathrm{L}_{2}=\mathrm{G}_{\mathrm{c}} \cdot \mathrm{b}[\mathrm{N} \cdot \mathrm{m}]
\end{aligned}
$$




$$
\mathrm{R}_{1}=\frac{\mathrm{G}_{\mathrm{c}} \cdot \mathrm{b}}{2 \cdot \mathrm{L}_{2}}, \mathrm{R}_{2}=\frac{\mathrm{G}_{\mathrm{c}} \cdot \mathrm{a}}{2 \cdot \mathrm{L}_{2}}[\mathrm{~N}]
$$

According to Figure 6a, it is possible to express by the relation (5a) the components of the force $\mathrm{R} 1$ and by the relation (5b) the components of the force R2. According to Figure $6 \mathrm{~b}$, it is possible to express it using the relation (6a) and based on the known value of the angle of gradient $\beta$ [deg] of the conical wheel, consequently the components of the force $\mathrm{T} 12$ and N12. The relation (6b) is applicable for the components of the force $\mathrm{T} 21$ and $\mathrm{N} 22$.

Figure $6 \mathrm{c}$ shows that the minimum value of the angle $\alpha_{\min }[\mathrm{deg}]$ of the supporting conical rollers of cast-iron moulds can be expressed according to the relation (7). Therefore, for the chosen diameter $\mathrm{Dk}=342 \mathrm{~mm}$ and $\mathrm{dk}=198.5 \mathrm{~mm}$ (Figure $4 b$ ), the value of $\alpha_{\min }$ equals $21.55 \mathrm{deg}$.

$$
\begin{aligned}
& \mathrm{R}_{11}=\mathrm{R}_{1} \cdot \sin \alpha, \mathrm{R}_{12}=\mathrm{R}_{1} \cdot \cos \alpha[\mathrm{N}] \\
& \mathrm{R}_{21}=\mathrm{R}_{2} \cdot \sin \alpha, \mathrm{R}_{22}=\mathrm{R}_{2} \cdot \cos \alpha[\mathrm{N}]
\end{aligned}
$$

Consequences of the technique of centering of cast-iron moulds by the rail system
Table 1 and Figure 7 show that the components of forces R11 (5a) and R21 (5b) increase along with the angle $\alpha$, whereas the components of forces R12 (5a) and R22 (5b) decline as the angle $\alpha$ increases.

If the supporting conical rollers are manufactured with the bevel angle of $\beta$ [deg] (see Figure $4 \mathrm{~b}$ and Figure $6 \mathrm{c}$ ), then the tangential component of the force T12 (Figure 6b) can be expressed according to the relation (6).

$$
\begin{gathered}
\mathrm{T}_{12}=\mathrm{R}_{12} \cdot \sin \beta, \mathrm{N}_{12}=\mathrm{R}_{12} \cdot \cos \beta[\mathrm{N}] \\
\mathrm{T}_{22}=\mathrm{R}_{22} \cdot \sin \beta, \mathrm{N}_{22}=\mathrm{R}_{22} \cdot \cos \beta[\mathrm{N}] \\
\alpha_{\text {min }}=\arcsin \frac{\mathrm{d}_{\mathrm{pmax}}}{\mathrm{D}_{\mathrm{k}}+\mathrm{d}_{\text {pmax }}}[\mathrm{deg}]
\end{gathered}
$$

The force component T12 (6a), (8a) tends to shift the rotating cast-iron mould to the wheel centre. The shift of the cast-iron mould would happen, if the force component T12 (8a) were higher that the friction force T1 (9a). The situation, where T12 T1 will happen, if the condition (10) is applicable.

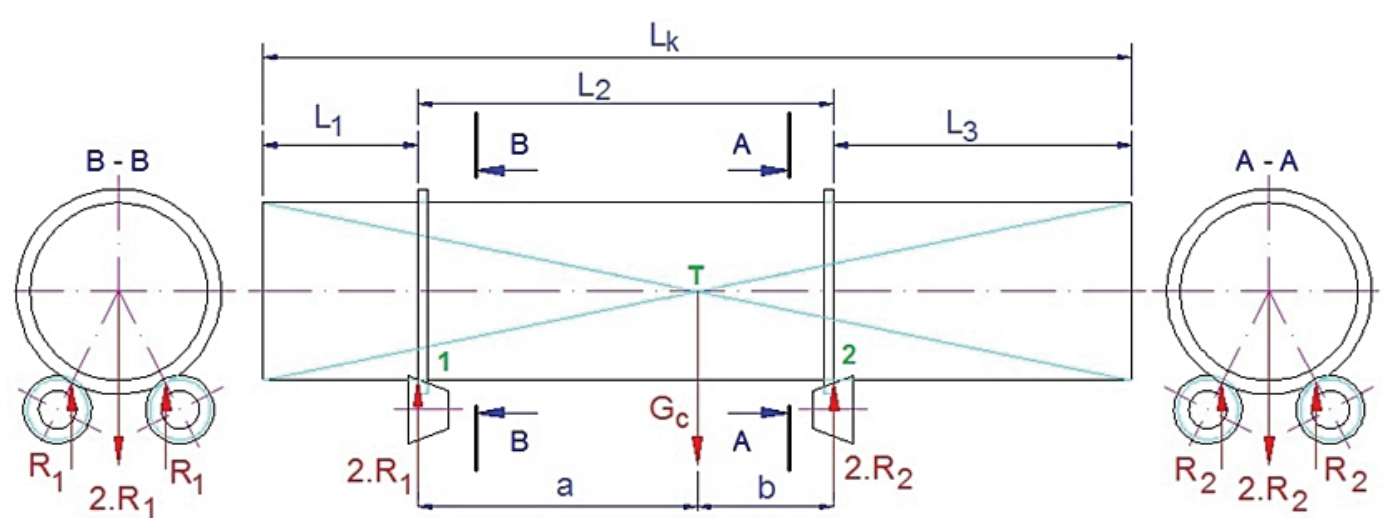

Fig. 5. Reactive forces acting on supporting rollers due to the cast-iron mould weight
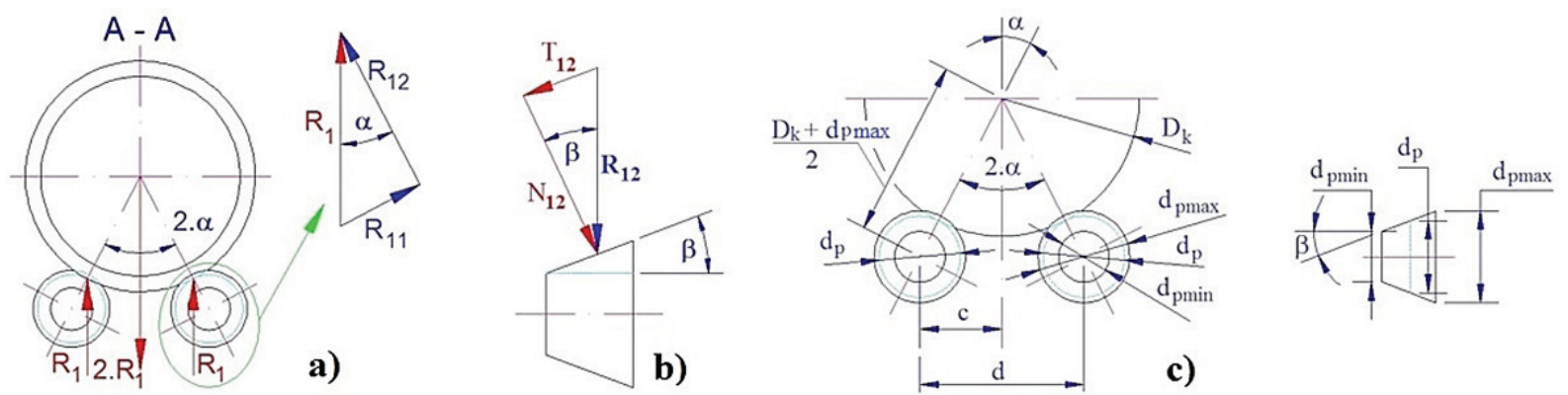

Fig. 6. Components of forces acting on supporting rollers due to the cast-iron mould weight 
Table 1 Dimension of angle $\alpha[\mathrm{rad}]$, values of $\cos (\alpha)$, and $\sin (\alpha)$ functions

\begin{tabular}{|l|c|c|c|c|c|c|c|c|c|c|}
\hline \multicolumn{1}{|c|}{$\alpha\left[^{\circ}\right]$} & 22 & 24 & 26 & 28 & 30 & 32 & 34 & 36 & 38 & 40 \\
\hline$\alpha[\mathrm{rad}]$ & 0.384 & 0.419 & 0.454 & 0.489 & 0.524 & 0.559 & 0.593 & 0.628 & 0.663 & 0.698 \\
\hline $\sin \alpha$ & 0.375 & 0.407 & 0.438 & 0.469 & 0.500 & 0.530 & 0.559 & 0.588 & 0.616 & 0.643 \\
\hline $\cos \alpha$ & 0.927 & 0.914 & 0.899 & 0.883 & 0.866 & 0.848 & 0.829 & 0.809 & 0.788 & 0.766 \\
\hline
\end{tabular}

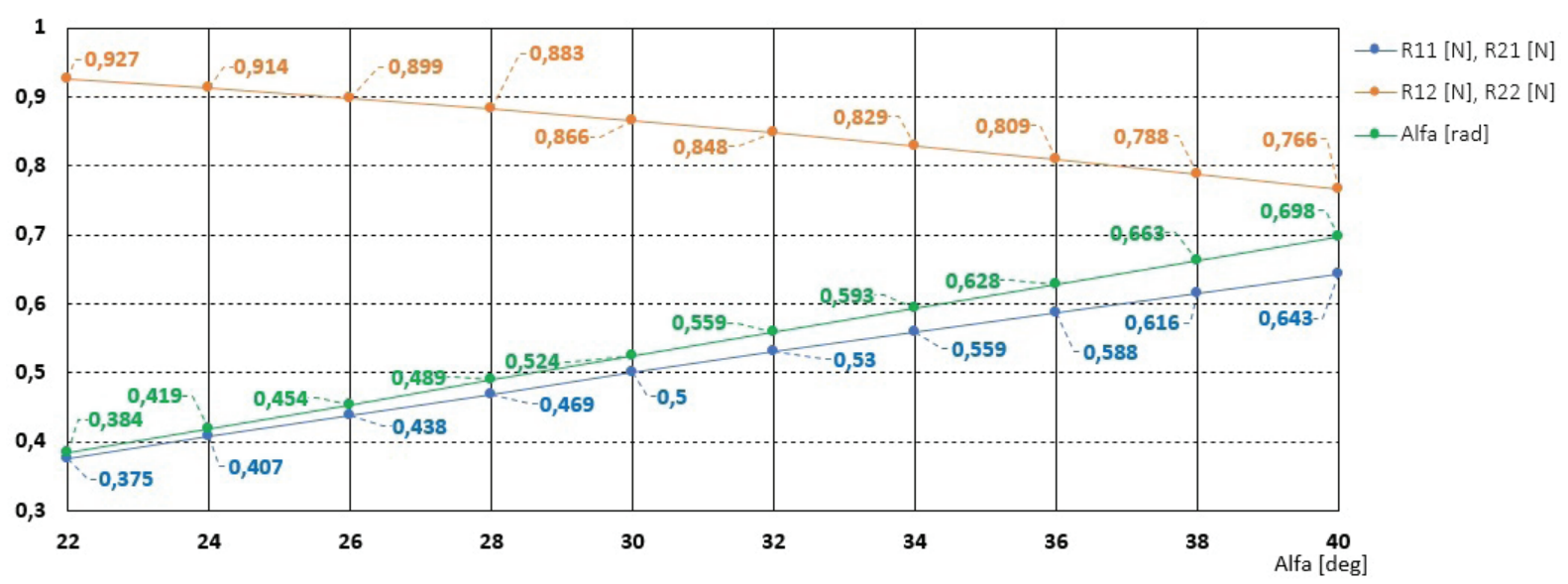

Fig. 7. Components of forces from R11 through to R22 acting on supporting rollers at the unit magnitudes of R1 and R2 forces

$$
\begin{gathered}
\mathrm{T}_{12}=\frac{\mathrm{G}_{\mathrm{c}} \cdot \mathrm{b}}{2 \cdot \mathrm{L}_{2}} \cdot \cos \alpha \cdot \sin \beta[\mathrm{N}] \\
\mathrm{T}_{22}=\frac{\mathrm{G}_{\mathrm{c}} \cdot \mathrm{a}}{2 \cdot \mathrm{L}_{2}} \cdot \cos \alpha \cdot \sin \beta[\mathrm{N}] \\
\mathrm{T}_{1}=\mathrm{N}_{12} \cdot \mathrm{f}=\frac{\mathrm{G}_{\mathrm{c}} \cdot \mathrm{b}}{2 \cdot \mathrm{L}_{2}} \cdot \cos \alpha \cdot \cos \beta \cdot \mathrm{f} \\
\mathrm{T}_{2}=\mathrm{N}_{22} \cdot \mathrm{f}=\frac{\mathrm{G}_{\mathrm{c}} \cdot \mathrm{a}}{2 \cdot \mathrm{L}_{2}} \cdot \cos \alpha \cdot \cos \beta \cdot \mathrm{f} \\
\mathrm{T}_{12} \geq \mathrm{T}_{1} \Rightarrow \beta \geq \arctan (\mathrm{f})[\mathrm{deg}]
\end{gathered}
$$

The manufacturer uses rollers with the bevel angle of $\beta \mathrm{s}=1: 15=0.067 \mathrm{rad}=3.82^{\circ}$ (Figure $\left.4 \mathrm{~b}\right)$.

If $\mathrm{b}<\mathrm{a}$ (Figure 5) then R2 $>\mathrm{R} 1$ and T22 $>$ T12 (Figure 6b) R22 > R12, from which it follows that the cast-iron mould will tend to shift in over the horizontal plane.
The cast-iron mould movement (tilt) from the left to the right will happen in the cases, where Fv $>0 \mathrm{~N}$ (13). If the cast-iron mould was moved to the right, then for $\beta>\beta 1$ (14) the right ring of the cast-iron mould would roll away along the smaller diameter of the right roller (Figure 4a) and thus it would have a lower circumferential speed. Conversely, the left ring of the cast-iron mould would roll away along the larger diameter of the left roller and thus it would have a higher circumferential speed. Because both left and right rings are tightly fixed to the cast-iron mould external surface, as well as considering that the cast-iron mould longitudinal centreline runs through the vertical plane, which is parallel with the plane running by the driving shaft centreline, no back shifting of the cast-iron mould to the position, where the cast-iron mould longitudinal centreline is parallel with the shaft centreline, can happen. Therefore, it is not possible for the technique of centering of cast-iron moulds in horizontal centrifugal casting

Table 2 Dimension of angle $\beta[\mathrm{rad}]$, values of $\cos (\beta), \sin (\beta)$ and $\cos (\beta) \cdot f$ functions

\begin{tabular}{|l|c|c|c|c|c|c|c|c|c|}
\hline \multicolumn{1}{|c|}{$\beta$ [deg] } & 0 & 2 & 4 & 5 & 5.71 & 6 & 10 & 15 & 20 \\
\hline$\beta$ [rad] & 0 & 0.035 & 0.070 & 0.087 & 0.1 & 0.105 & 0.175 & 0.262 & 0.349 \\
\hline $\sin \beta$ & 0 & 0.035 & 0.070 & 0.087 & 0.1 & 0.105 & 0.174 & 0.259 & 0.342 \\
\hline $\cos \beta$ & 1 & 0.999 & 0.998 & 0.996 & 0.995 & 0.995 & 0.985 & 0.966 & 0.940 \\
\hline $\mathrm{f} \cdot \cos \beta$ & 0.1 & 0.1 & 0.1 & 0.1 & 0.1 & 0.099 & 0.098 & 0.097 & 0.094 \\
\hline
\end{tabular}




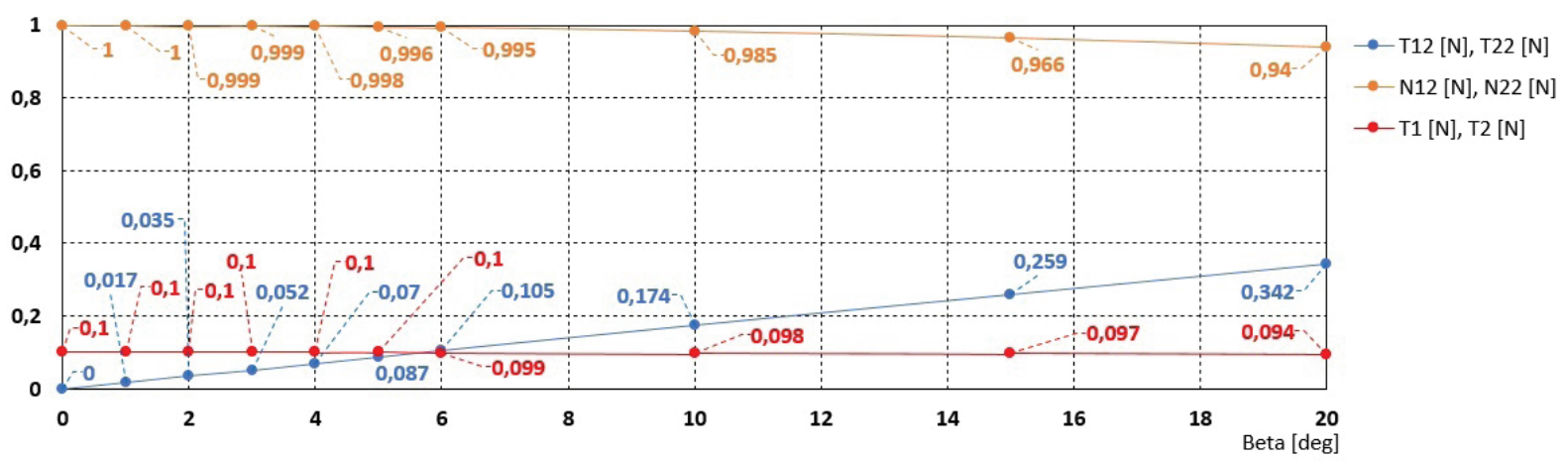

Fig. 8. Components of tangential forces T12 and T22 and frictional forces T1 and T2 at the unit magnitudes of forces R11 and R22

of metals to apply an idea, which is valid for the passing through a curved track, i.e. that "by shifting the pair of wheels from the track centreline towards the outer rail will result in an effect where circles of contact of both wheels define a cone with its apex in the centre of the curve and the pair of wheels passes through the curved track without rotational wheel slips [14]".

According to Figure 9, it is possible to set up equations (11) and (12) expressing the equilibrium of forces acting on the surfaces (inclined under the angle $\beta$ [deg]) of conical rollers during the cast-iron mould movement from the left side to the right side.

$$
\begin{aligned}
\mathrm{F}_{\mathrm{s}} & =\mathrm{R}_{22} \cdot(\sin \beta-\cos \beta \cdot \mathrm{f})[\mathrm{N}] \\
\mathrm{F}_{\mathrm{z}} & =-\mathrm{R}_{12} \cdot(\sin \beta+\cos \beta \cdot \mathrm{f})[\mathrm{N}] \\
\mathrm{F}_{\mathrm{v}} & =\mathrm{F}_{\mathrm{s}}+\mathrm{F}_{\mathrm{z}}=\sin \beta \cdot\left(\mathrm{R}_{22}-\mathrm{R}_{12}\right)- \\
& -\cos \beta \cdot \mathrm{f} \cdot\left(\mathrm{R}_{12}+\mathrm{R}_{22}\right)[\mathrm{N}]
\end{aligned}
$$

$$
\beta_{1}=\arctan \frac{\mathrm{f} \cdot\left(\mathrm{R}_{12}+\mathrm{R}_{22}\right)}{\mathrm{R}_{22}-\mathrm{R}_{12}}[\mathrm{deg}]
$$

The conical nature (taper ratio) of the supporting driving and driven rollers causes that in the movement from the central position (see Figure 10) at the right roller, the circle involving the contact points of the roller with the ring, i.e. the contact circle of diameter $\mathrm{d} 0[\mathrm{~m}]$, will move in the direction to the wheel flange and, at the same time, its diameter will increase. Correspondingly, with the left roller, the contact circle will move in the direction from the wheel flange and, at the same time, its radius will decrease.

In Figure 10, the cross traverse is marked as $\Delta \mathrm{x}[\mathrm{m}]$ of radiuses of the contact circles and the incline of the conical surface (the so-called conical nature or taper ratio) of roller as $\beta$ [deg]. For the tapered surfaces of the rollers, the following characteristic applies (15) and (16).

$$
\mathrm{r}_{\mathrm{p}}=\mathrm{r}_{0}-\Delta \mathrm{x} \cdot \tan \beta[\mathrm{m}]
$$
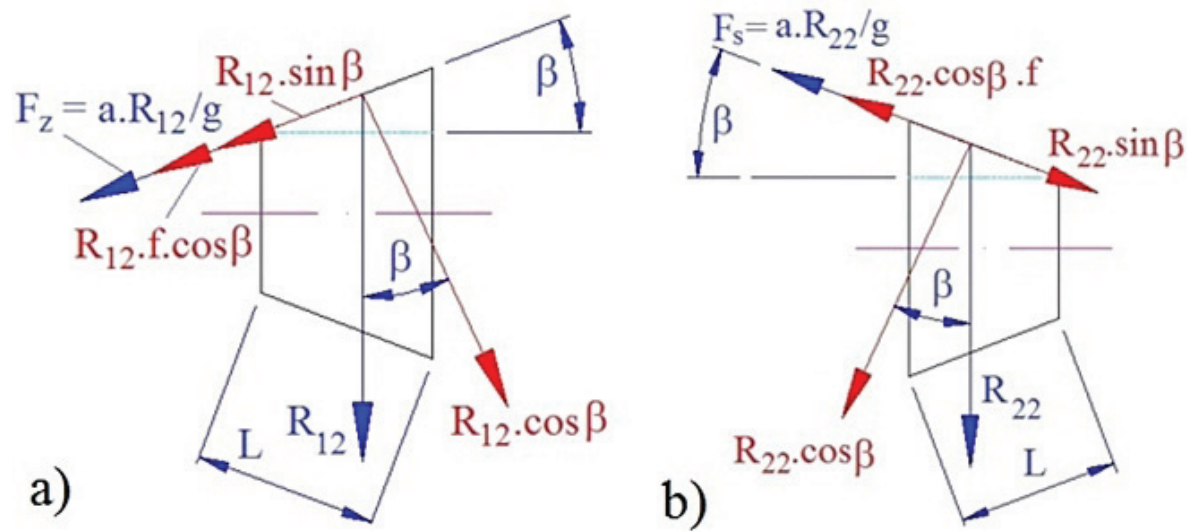

Fig. 9. Forces acting on the a) left, b) right roller during the cast-iron mould movement from the left to the right, i.e. Fv $>0 \mathrm{~N}$ 
a)

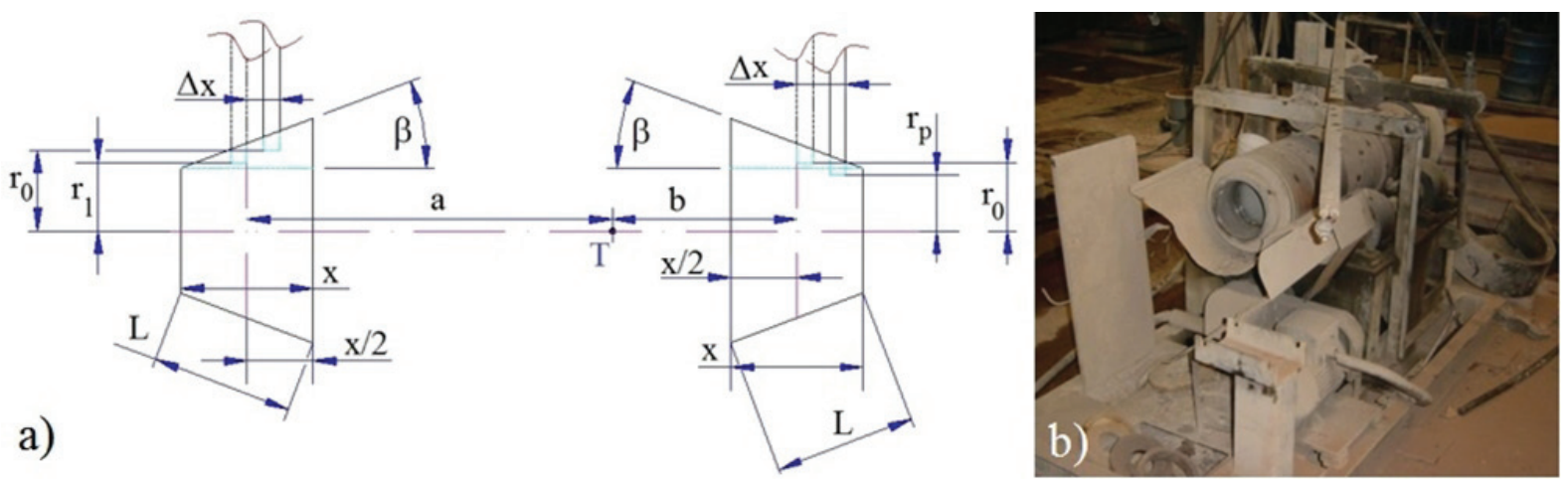

Fig. 10. a) Contact circle radiuses for left and right conical rollers,

b) cast-iron mould at its horizontal centrifugal casting

$$
\mathrm{r}_{1}=\mathrm{r}_{0}+\Delta \mathrm{x} \cdot \tan \beta[\mathrm{m}]
$$

By the displacement of the cast-iron mould centre of gravity by the value of $\Delta x[\mathrm{~m}]$ (see Figure 10) towards the right roller, the achieved effect will cause that the right ring of the cast-iron mould will rotate in a slower circumferential speed vp (17) than the left ring of the cast-iron mould vl (18). As the cast-iron mould rotates at revolutions of nk [s-1], a slip of the cast-iron mould rings on the driving rollers takes place.

$$
\begin{aligned}
& \mathrm{v}_{\mathrm{p}}=\mathrm{r}_{\mathrm{p}} \cdot \omega=\mathrm{r}_{\mathrm{p}} \cdot 2 \cdot \pi \cdot \mathrm{n}\left[\mathrm{m} \cdot \mathrm{s}^{-1}\right] \\
& \mathrm{v}_{1}=\mathrm{r}_{1} \cdot \omega=\mathrm{r}_{1} \cdot 2 \cdot \pi \cdot \mathrm{n}\left[\mathrm{m} \cdot \mathrm{s}^{-1}\right]
\end{aligned}
$$

\section{CONCLUSIONS}

In the introduction to this paper, the advantages and two utilised principles of axial centering of cast-iron moulds were described or outlined, respectively, as well as basic methods of centrifugal casting specified.

The effort of KonCAD CZ s.r.o. in the search for replacements of the currently widely employed methods of axial centering of cast-iron moulds in the horizontal centrifugal casting techniques resulted in an idea to use for the axial centering the findings acquired from passing of a rail vehicle through a curved track. KonCAD CZ s.r.o. prepared a draft design of 3D model of an innovative, the so-called rail system as a solution for the cast-iron mould axial centering. Before a prototype of the centrifugal casting machine was prepared according to this solution for the cast-iron mould axial centering, the Faculty of Mechanical Engineering, VSB-Technical University of
Ostrava had been asked for processing the calculations proving (or disproving) that the cast-iron mould axial centering by the use of the rail system was appropriate for practical purposes.

However, the conclusions from the theoretical considerations and calculations as shown in this paper did not permit to approve this innovative solution for the cast-iron mould axial centering because it was not possible to apply the theory of passing of a rail vehicle through a curved track in this case.

If the axial displacement $\Delta x[\mathrm{~m}]$ of the rotating cast-iron mould against the centre of the length $\mathrm{x}[\mathrm{m}]$ of the width of conical (tapered) rollers takes place, then the horizontal forces, which might straighten the longitudinal axis of the cast-iron mould deflected from the horizontal plane, will not be generated.

\section{Acknowledgements}

This work has been supported by The Ministry of Education, Youth and Sports of the Czech Republic from the Specific Research Project SP2020/90.

\section{REFERENCES}

1. Wei Sufei, Lampman Steve. 2008. "Centrifugal Casting”. ASM Handbook, 15: 667-673. ISBN: 978-1-62708-026-2. DOI: 10.1361/asmhba0005257.

2. Durna A., Fries J., Hrabovsky L., Sliva A. and Zarnovsky J. Research and development of laser engraving and material cutting machine from 3D printer. Management Systems in Production Engineering, 28(1), 2020, 47-52.

3. Hrabovsky L. and Dluhos D. Limit Calibration of Transducers and of a Coil Compression Spring 
Constant on the Testing Equipment Simulating the Process of a Pallet Positioning in a Rack Cell. Open Engineering, 9(1), 2019, 631-640.

4. Hrabovsky L. Mlcak T. and Kotajny G. Forces generated in the parking brake of the pallet locking system. Advances in Science and Technology Research Journal, 13(4), 2019, 181-187.

5. Mantic M., Kulka J., Kopas M., Faltinova E. and Hrabovsky L. Limit states of steel supporting structure for bridge cranes. Scientific Journal of Silesian University of Technology. Series Transport. 108, 2020, 141-158.

6. Virgl V. (2015)., ,Výroba odlitků ze slitin železných a neželezných kovů odstředivým litím.” Bc. thesis, Vysoké Učení Technické v Brně. [In Czech: Virgl V. 2015. "Manufacture of centrifugal castings from iron and non-ferrous alloys". Bac. thesis. Brno University of Technology].

7. Zanda M. (2017). "Výroba odlitků z železných a neželezných slitin odstředivým litím“. Ing. thesis, Vysoké Učení Technické v Brně. [In Czech: Zanda M. 2017. „Manufacture of Centrifugal Castings from Iron and Non-iron Alloys". Thesis. Brno University of Technology].
8. KonCAD CZ. Available at: https://www.koncad. cz/\#portfolio (In Czech) (Access: 20.02.2019).

9. MEDEKO. Available at: https://www.medeko.sk/ en/centrifugal-casting (Access: 20.06.2020).

10. MIMOZA. Available at: http://mimoza.marmara. edu.tr/ altan.turkeli/files/cpt-9-centrifugal_casting.pdf (Access: 14.09.2011).

11. Slide Player. Available at: https://slideplayer.cz/ slide/15221446/ (In Czech) (Access: 29.07.2020).

12. Technometal. Available at: www.unibar.cz/odstredive-lite-bronzy-mosazi (In Czech) (Access: 05.08.2020).

13. THE LIBRARY OF MANUFACTURING. Available at: http://thelibraryofmanufacturing.com/ (Access: 17.05.2015.).

14. VUHZ. Available at: www.vuhz.cz/odstredive-odlitky/princip-odstrediveho-liti (In Czech) (Access: 29.07.2020).

15. Wikipedia. Available at: https://cs.wikipedia.org/ wiki/Pr\%C5\%AFjezd_obloukem (In Czech) (Access: 05.06.2020).

16. Centrifugal Casting (3D Animation). Available at: www.youtube.com/watch?v=NIPM2pnL9bQ (Access: 29.07.2020). 